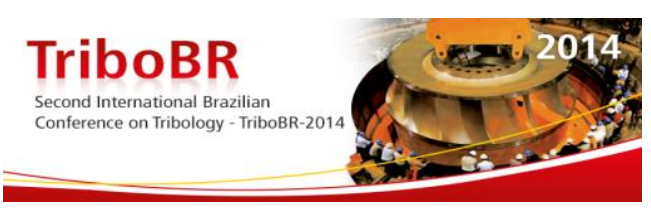

\title{
EFFECT OF LINER TEXTURE ON RING/LINER TRIBOLOGICAL PERFORMANCE*
}

\author{
Hugo M. Checo ${ }^{1}$ \\ Mohammed Jair \\ Gustavo C. Buscaglia ${ }^{3}$
}

\begin{abstract}
Friction-reducing textures for lubricated mechanisms have received much attention since the advent of microtexturing techniques. In this work we consider the piston ring/liner contact, numerically simulating the rings as they slide against a textured liner. This situation has not been sufficiently analyzed because its numerical complexity is much greater than that of texturing the rings. Further, we consider the actual typical geometries of oil-control, wiper and compression rings, under realistic loads and velocities. The results show the possibility of friction reduction when the texture on the liner is properly designed, identifying starvation alleviation as a crucial intervening mechanism.

Keywords: Laser texture; Cylinder liner; Piston ring; Mass-conservative model; Friction; Fourstroke cycle.
\end{abstract}

1 PhD student, Instituto de Ciências Matemáticas e de Computação, Universidade de São Paulo, São Carlos, São Paulo, Brazil.

2 PhD, researcher at Intitut Camille Jordan, Institut Nationale des Sciences Appliquées de Lyon, Lyon, France.

$3 \quad \mathrm{PhD}$, researcher at Instituto de Ciências Matemáticas e de Computação, Universidade de São Paulo, São Carlos, São Paulo, Brazil.

\footnotetext{
* Technical contribution to the $2^{\text {nd }}$ International Brazilian Conference on Tribology - TriboBR 2014,
} November $3^{\text {rd }}$ to $5^{\text {th }}$, 2014, Foz do Iguaçu, PR, Brazil. 


\section{INTRODUCTION}

One of the largest contributors to the mechanical losses in an internal combustion engine is the ring/liner conjunction, which accounts for about $5 \%$ of fuel consumption [1]. Low emissions, reduced friction and low lubricant consumption are the conflicting goals in the design process of a lubrified pair [2].

Lately, friction reduction in the piston ring/liner contact is the subject of intense research with diverse solutions being proposed and studied. Among them surface texturing stands as an attractive alternative, since a significant number of experimental and theoretical works have demonstrated its feasibility [3-6].

Most works on friction reduction (both numerical and experimental) with textured surfaces for the ring/liner contact focused on texturing the ring rather than the liner $[7,8]$. This might not be the optimal choice, as the rings undergo wear during their lifetime and textures could merely last the break-in [9]. The simulation of the ring/liner contact with texture on the liner also constitutes a challenge from the numerical perspective. The dynamical behavior of the system is completely different depending on whether the texture is on the ring or on the liner: a textured liner implies an oscillatory motion of the rings, and thus the simulation must be transient and also must incorporate the rigid-body dynamics of the ring, which is subject to time-varying forces.

Experimental and numerical works on textured liners in contact with ring packs in reciprocating motion are scarce. The experimental tests of Guo et al [10] only assessed friction through surface wear. Yin et al [11] solved the problem for a dimpled liner with an oversimplified (rectangular, single-ring) ring pack. Similarly, Liao et al [12] considered just the oil control ring in their studies of honed liners. The simulations reported here consider a much more realistic setting. Actual ring profiles are simulated combined in a complete ring pack, composed of compression, wiper and oil control rings. The gas pressure and piston dynamics correspond to those of a typical four-stroke diesel engine at $2000 \mathrm{rpm}$.

This works is organized as follows: in section 2 the mathematical model is presented. The numerical method is introduced in section 3, while the numerical results are contained in section 4. Finally, conclusions are drawn in section 5 .

\section{MODEL}

A thin stripe of the liner surface in the piston movement direction is the computational domain, as shown in figure 1. The direction of the motion of the piston is chosen to be $x_{1}$, while the runner is assumed to coincide with the $x_{1}-x_{2}$ plane. The frame of reference is fixed on the ring and thus we assume that the liner moves with velocity $u$.

\footnotetext{
* Technical contribution to the $2^{\text {nd }}$ International Brazilian Conference on Tribology - TriboBR 2014,
} November $3^{\text {rd }}$ to $5^{\text {th }}$, 2014, Foz do Iguaçu, PR, Brazil. 


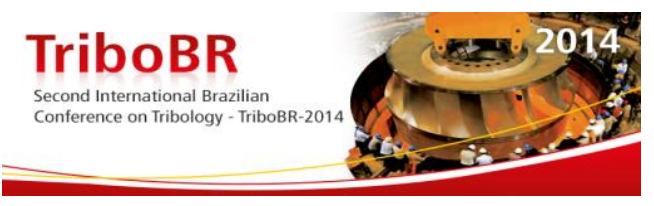

(a)

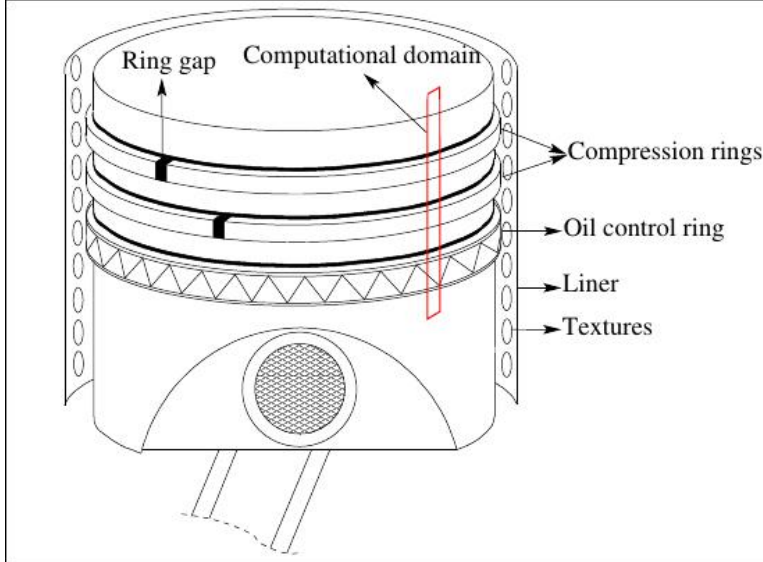

(b)

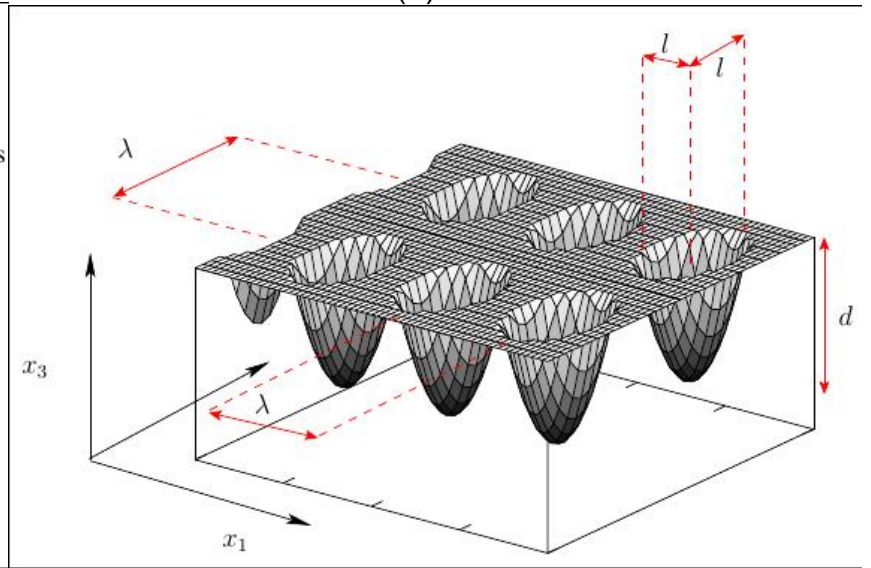

Figure 1: Figure (a) shows a scheme of a ring pack placed in the piston. The computational domain is bounded by a red rectangle while figure (b) depicts the pockets on the liner surface, resembling the ones produced with Laser Surface Texturing. $\lambda, l$ and $d$ are the texture's period, radius and depth.

Textures on the liner are arranged on a two-dimensional square lattice of semiellipsoidal pockets with semi-axis $l_{1}=l, l_{2}=l$ (circular cross-section) and $d$, as depicted in figure 1 (b). The separation between contiguous textures is $\lambda$ (the texture's period). This texture is described by the function $x_{3}=-h_{L}\left(x_{1}, x_{2}, \mathrm{t}\right)$, being $h_{L}\left(x_{1}, x_{2}, \mathrm{t}\right)=0$ for the untextured liner. $h_{L}$ is periodic in both $x_{1}$ and $x_{2}$ directions, therefore $0<x_{1}<w$, with $w$ large enough to contain one texture period. In the $x_{1}$ direction the domain extent is $x_{l}<x_{1}<x_{r}$.

Each ring has a length $L_{i}$ and is located at $x_{l}<a_{i}<x_{1}<b_{i}<x_{r}$. Their profiles $h_{U_{i}}\left(x_{1}, x_{2}\right)$ satisfy $\min _{x_{1}, x_{2}} h_{U_{i}}\left(x_{1}, x_{2}\right)=0$. A uniform thickness $e$ is assumed outside the ring's locations. Hence, we have for the gap between the liner and the ring:

$$
h\left(x_{1}, x_{2}, t\right)= \begin{cases}h_{L}\left(x_{1}-u t, x_{2}\right)+h_{U_{i}}\left(x_{1}, x_{2}\right)+Z_{i}(t) & \text { if } a_{i}<x_{1}<b_{i} \\ h_{L}\left(x_{1}-u t, x_{2}\right)+e & \text { otherwise }\end{cases}
$$

where $Z_{i}(t)$ denotes the vertical distance between the ring and the $x_{1}-x_{2}$ plane. The resulting functions $h_{L}$ and $h_{U_{i}}$ are shown in figure 2 for the arrangement assessed in this work.

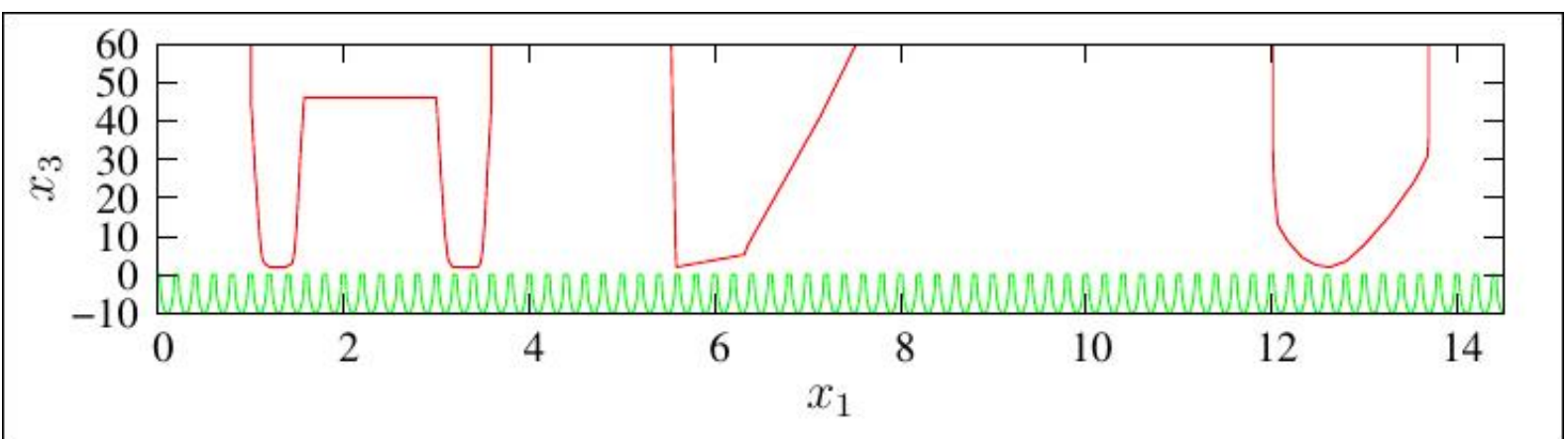

Figure 2: Ring profiles and arrangement in the computational domain.

Along with the geometrical configuration of the problem we also need to model:

1. The fluid dynamics,

2. The ring dynamics (forces acting on it).

* Technical contribution to the $2^{\text {nd }}$ International Brazilian Conference on Tribology - TriboBR 2014, November $3^{\text {rd }}$ to $5^{\text {th }}$, 2014, Foz do Iguaçu, PR, Brazil. 


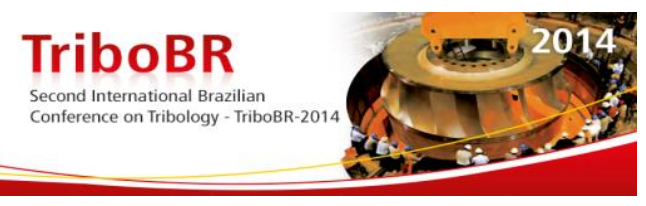

\subsection{Thin Film Fluid Dynamics with Cavitation}

The very thin gap between the ring and liner allows the use of the lubrication approximation (Reynolds equation). Due to the convergent-divergent geometry of the ring/textured liner contact and to the movement of the ring in its placement, cavitation takes place. In this work we adopt the well-known Elrod-Adams model [13] which incorporates into a single formulation the Reynolds equation for the pressurized region and the Jacobsson-Floberg-Olsson boundary conditions for cavitation. Comparison between results with this mass-conserving model and experiments show excellent agreement [14].

The model postulates the computation of two fields, $p$ and $\theta$, which correspond to the hydrodynamic pressure and to an auxiliary saturation-like variable, respectively, that (weakly) satisfy the equation

$$
\nabla \cdot\left(\frac{h^{3}}{12 \mu} \nabla p\right)=\frac{u(t)}{2} \frac{\partial h \theta}{\partial x_{1}}+\frac{\partial h \theta}{\partial t}
$$

under the complementarity conditions

$$
\left\{\begin{array}{l}
p>0 \quad \Rightarrow \quad \theta=1 \\
\theta<1 \quad \Rightarrow \quad p=0 \\
0 \leq \theta \leq 1
\end{array}\right.
$$

where $\mu$ is the viscosity of the lubricant. Initial conditions for $\theta$ and $p$ are provided. A constant film thickness of lubricant $d_{l u b}$ is assumed upstream of the ring.

At each instant the domain spontaneously divides into a pressurized region, $\Omega^{+}$, where $p>0$, and a cavitated region, $\Omega^{0}$, where the film is not full $(\theta<1)$. At the boundary between $\Omega^{+}$and $\Omega^{0}$, the so-called cavitation boundary $\Sigma$, the Elrod-Adams model automatically enforces mass-conservation.

\subsection{Ring Dynamics}

Several forces act on each ring $i(i=1,2,3)$ in the $x_{3}$ direction:

1. The pre-stress force $W_{i}^{p s}$ : pointed downwards (i.e.; along $-x_{3}$ ) and assumed constant. Comes from the elastic response of the ring to the deformation needed to fit its placement. The values per unit width adopted here are $W_{1}^{p s}=-$ $704 \mathrm{~N} / \mathrm{m}$ (oil control ring), $W_{2}^{p s}=-290 \mathrm{~N} / \mathrm{m}$ (wiper ring) and $W_{3}^{p s}=-325 \mathrm{~N} / \mathrm{m}$ (compression ring);

2. The hydrodynamic force $W_{i}^{h}(t)$ : originates from the pressure $p\left(x_{1}, x_{2}, t\right)$ that develops in the ring/liner bearing:

$$
W_{i}^{h}(t)=\frac{1}{w} \int_{a_{i}}^{b_{i}} \int_{0}^{w} p\left(x_{1}, x_{2}, t\right) d x_{1} d x_{2}
$$

3. The contact force $W_{i}^{c}(t)$ : exerted by one surface to the other due to the direct contact between asperities:

$$
W_{i}^{c}(t)=\frac{1}{w} \int_{a_{i}}^{b_{i}} \int_{0}^{w} p_{c o n}\left(x_{1}, x_{2}, t\right) d x_{1} d x_{2}
$$

where $p_{c o n}$ is the contact pressure.

\footnotetext{
* Technical contribution to the $2^{\text {nd }}$ International Brazilian Conference on Tribology - TriboBR 2014, November $3^{\text {rd }}$ to $5^{\text {th }}, 2014$, Foz do Iguaçu, PR, Brazil.
} 


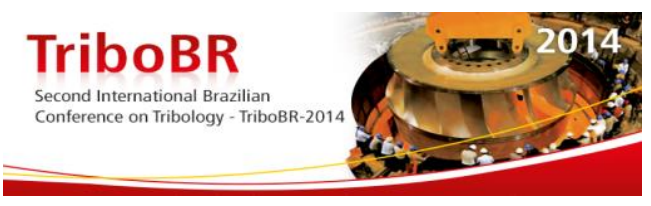

4. The gas pressure force $W_{i}^{g p}(t)$ : its the force produced by the pressure of the combustion gases acting on the back part of the rings. This force its timedependent, and its value per unit width its assumed to be:

$$
W_{i}^{g p}(t)=-\varphi_{i} L_{i} p_{c}(t)
$$

$p_{c}(t)$ is shown in figure $3(\mathrm{~b})$ as a function of the crank angle. Here we take $\varphi_{3}=0.9$, $\varphi_{2}=0.25$ and $\varphi_{1}=0.0$.

The contact pressure $p_{\text {con }}$ is given by the the Greenwood-Williamson model [15] as approximated by the Panayi-Schock formula [16]. Realistic values are taken for the standard deviation of asperities height, $\sigma=0.04 \mu \mathrm{m}$ and for the composite modulus $E^{\prime}=100 \mathrm{GPa}$.

No tilting of the rings is assumed, and thus the dynamics is given by Newton's second law in the $x_{3}$ direction:

$$
m_{i} \frac{d^{2} Z_{i}}{d t^{2}}=W_{i}^{p s}+W_{i}^{h}(t)+W_{i}^{c}(t)+W_{i}^{g p}(t)
$$

where $m_{i}$ is each ring's linear mass. The linear masses, $\varphi_{i}$ factors and the parameters of the geometric configuration of the ring pack are given in table 1.

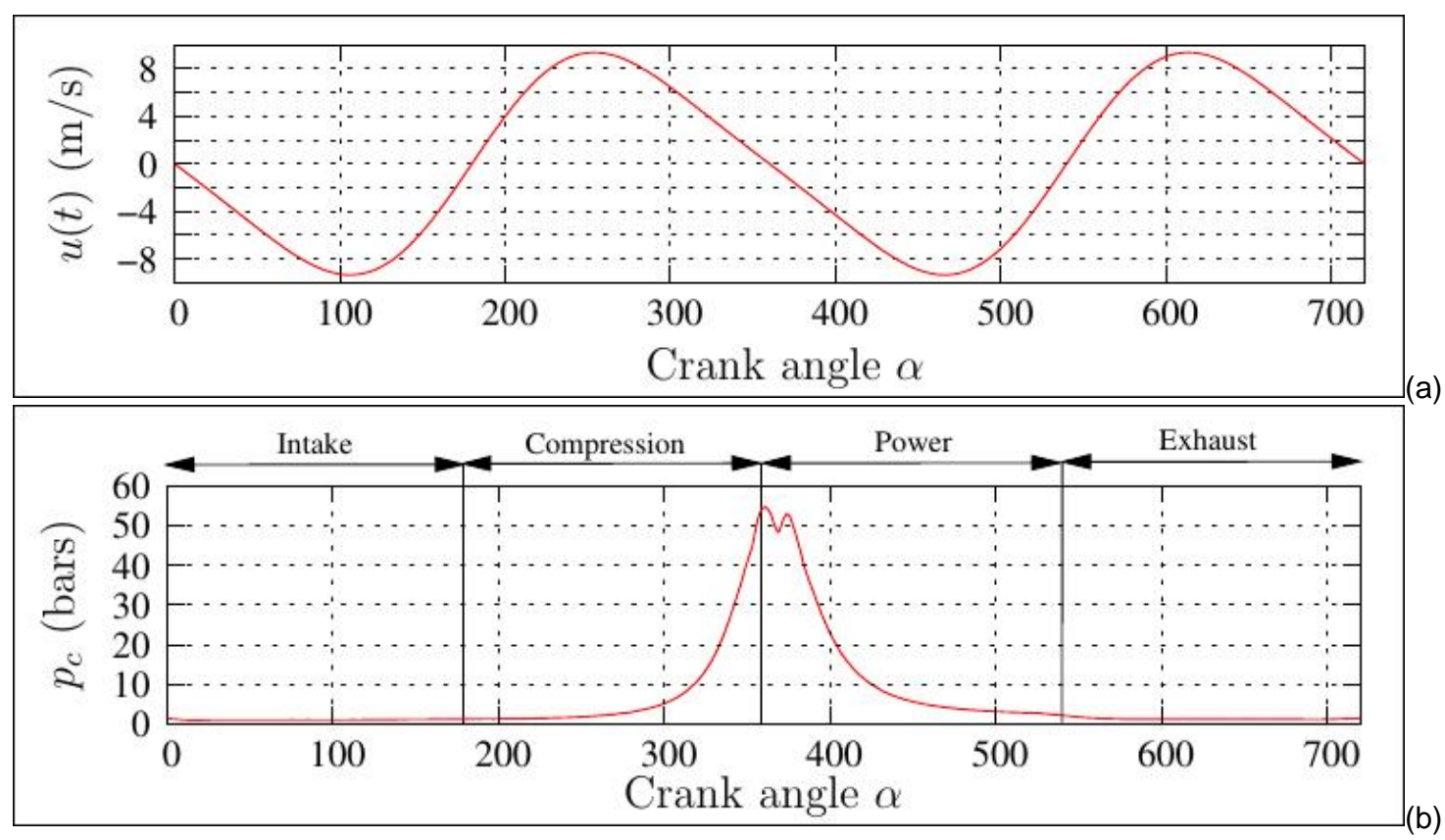

Figure 3: (a) Piston velocity and (b) combustion chamber pressure along the four-stroke engine cycle of a diesel engine at $2000 \mathrm{rpm}$.

Table 1: Ring's data.

\begin{tabular}{lccccc}
\hline Ring & $L_{i}(\mathrm{~mm})$ & $a_{i}(\mathrm{~mm})$ & $b_{i}(\mathrm{~mm})$ & $m_{i}(\mathrm{~kg} / \mathrm{m})$ & $\varphi_{i}$ \\
\hline Compression & 1.7 & 12.0 & 13.7 & 0.03 & 0.9 \\
\hline Wiper & 2.1 & 5.5 & 7.6 & 0.05 & 0.25 \\
\hline Oil control & 2.6 & 1.0 & 3.6 & 0.05 & 0.0 \\
\hline
\end{tabular}

\section{NUMERICAL METHOD}

The numerical treatment is exactly as described in [17]. It consists of a finite volume, conservative method with upwinding discretization of the Couette flux and centered discretization of the Poiseuille flux and an iterative imposition of the cavitation conditions by means of a Gauss-Seidel-type algorithm. 


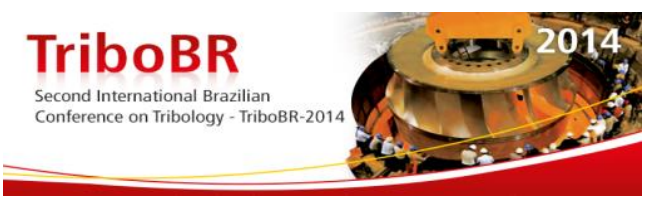

The dynamical equation for $Z_{i}(t)$ is discretized by a Newmark scheme, which is built into the overall iterative process. The simulations would not have been possible without significant acceleration obtained from multigrid techniques ([18]).

\section{NUMERICAL TESTS}

Two simulations were performed: the first with an untextured liner and the second with the previously defined square arrangement of semi-ellipsoidal dimples. For the latter $l=0.075 \mathrm{~mm}, d=10 \mu \mathrm{m}$ and $\lambda=0.2 \mathrm{~mm}$ thus giving a total textured area of $44.2 \%$. The initial film thickness as the lubricant feeding conditions are set to $d_{l u b}=$ $5.0 \mu \mathrm{m}$.

The domain size is such that $x_{l}=0, x_{r}=14.5 \mathrm{~mm}$ and is discretized in $2048 \times 16$ finite volumes with a time step such that the maximum Courant number is 1.56 at maximum piston velocity.

Two instantaneous quantities are extracted from the simulations, once the transients have passed and a periodic regime has been established (for this study it required three engine cycles):

a) The minimum clearance $C_{i}(t)$;

b) The friction force per unit width $F_{i}(t)$.

Results for $C_{i}$ (in microns) are seen in figure 4, with the clearance for the fully textured liner shown with a full line. The dotted lines are reserved for the untextured liner. This is kept for all following figures.

\subsection{Clearance}

A logical way to assess the outcome of the simulations is to study the effects of texturing in clearance for the four engine strokes: intake, compression, power and exhaust; then the texturing effects in friction force can be easily explained.

A relevant aspect determining the oil film thickness along the engine cycle is the notorious asymmetry of the profiles of both compression and wiper rings. From Top Dead Center (from now on, TDC) to Bottom Dead Center (intake, power) they have reduced load carrying capacity and thus experience much lower mean clearances. On the other hand, from BDC to TDC (compression, exhaust) they have a moderate wedge that grants larger clearances. This trend is common for both rings as seen in figure 4.

The minimum clearance curve of the oil control ring accompanies the piston ring velocity curve, as it is almost symmetrical in the $x_{1}$ direction and does not withstand the gas pressure forces $\left(\varphi_{1}=0\right)$. In consequence, clearances are quite similar in the down and upstrokes. This is true for both the textured and untextured liners, although the textures have a detrimental effect on $C$, which is diminished from 0.64 (untextured) to 0.30 (both average values of the complete engine cycle).

Now that this broader overview of the results has been set, we can focus on the compression and wiper rings and grasp finer details of the ring's dynamics:

a) Intake ( 0 to 180 degrees): In the interval $0<\alpha<65$ the compression ring clearance increases due to the recently deposited oil during the exhaust. At approximately $\alpha=65$ for the untextured liner and $\alpha=55$ for the textured one, the starvation effect of the little oil left by the wiper ring is felt, with a significant dropoff in $\mathrm{C}$. From this point on, the compression ring for the untextured liner stays in the mixed to boundary lubrication regime, the load being held mostly by the contact force, while for the textured liner there is

\footnotetext{
* Technical contribution to the $2^{\text {nd }}$ International Brazilian Conference on Tribology - TriboBR 2014,
} November $3^{\text {rd }}$ to $5^{\text {th }}$, 2014, Foz do Iguaçu, PR, Brazil. 


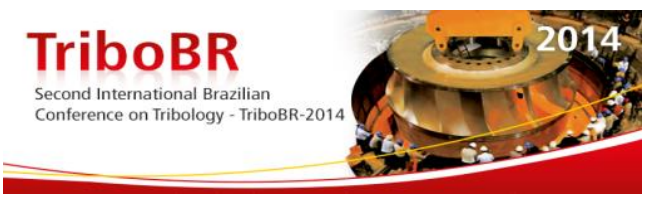

enough oil to generate some carrying capacity and separate the surfaces. This "extra" oil comes from two sources: a) the oil trapped in the dimples and afterwards; b) from the oil supplied in behalf of the oscillating movement of the wiper ring, from $\alpha=70$ to $\alpha=135$.

b) Compression (180 to 360 degrees): As the sides with larger load carrying capacity face upwards for the compression and wiper rings, clearances increase with velocity. When the TDC is approached, the pressure in the combustion chamber grows rapidly. This causes a severe drop in $\mathrm{C}$, which is faster for the compression ring. The textures have a deleterious effect on clearance, being $\mathrm{C}$ much lower for the textured liner.

c) Power (360 to 540 degrees): Results can be appraised realizing that the power stroke is similar to the intake with a large load decreasing from TDC to BDC. By that reason clearances are much lower, although they still present the same behavior as in the intake stroke. A brisk decline is seen again due to starvation at $\alpha=428$ for the compression ring with the untextured liner, while for the textured a slight increase in $\mathrm{C}$ is observed from approximately that same point until $\alpha=530$.

d) Exhaust (540 to 720 degrees): During the exhaust, the piston experiences the same dynamics as in the compression event but the pressure in the combustion chamber is lower (atmospheric or nearly) and virtually constant along the stroke. This leads to an analogous disposition of the clearances, even though they are larger and more widespread for both compression and wiper rings by virtue of the lower loads.

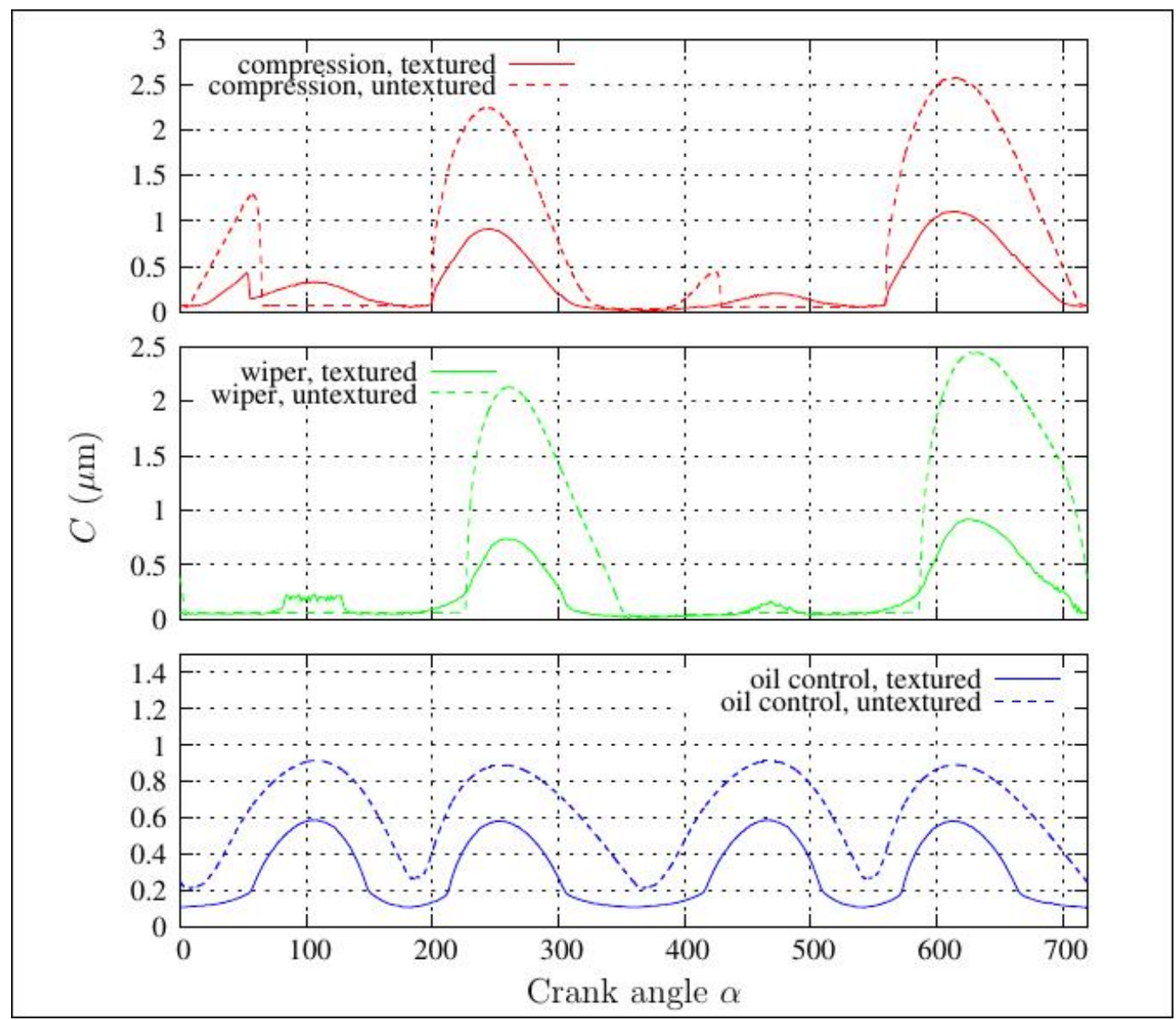

Figure 4: Minimum clearance for the three rings, from top to bottom: compression, wiper and oil control ring.

* Technical contribution to the $2^{\text {nd }}$ International Brazilian Conference on Tribology - TriboBR 2014, November $3^{\text {rd }}$ to $5^{\text {th }}$, 2014, Foz do Iguaçu, PR, Brazil. 


\subsection{Friction Force}

Figure 5 portrays the dimensionless friction force for each ring. Maximum friction is attained coincident with lower velocities and particularly for the compression and wiper rings, with higher gas pressures.

The compression ring endures the highest friction forces $(844.8 \mathrm{~N} / \mathrm{m}$ ), followed by the wiper ring $(331.6 \mathrm{~N} / \mathrm{m})$ and the oil control ring $(78.0 \mathrm{~N} / \mathrm{m})$. For the first two, this is attained at the TDC immediately after the power stroke begins $(\alpha=360)$. The friction at this point is significantly higher than for the rest of the engine cycle, and the maximum value is not influenced by the liner texturing. Close to the TDC during the compression-power stages textures have a detrimental effect, increasing friction.

Despite this situation, at mid-stroke where higher velocities takes place significant reductions in friction can be achieved. This is seen for the compression ring in the intervals $65<\alpha<200$ and $429<\alpha<560$. The intervals where this happens for the wiper ring are more numerous. The pocketed liner induces more friction for the oil control ring (figure 4), especially at and near dead centers. Little reduction is seen at mid-stroke. These results hint about not texturing close to the dead centers, especially near the TDC, thereby avoiding the regions where texturing increases the friction.

The friction force can be separated in its contact and hydrodynamic parts, as is shown in figure 6 . It can be noticed that the hydrodynamic components for the three rings are similar in magnitude and slightly higher for the untextured liner all along the engine cycle, while the largest friction values are due mainly to the contact force. The reductions in friction discussed in the previous paragraph were possible as a result of a marked decrease in the contact force.

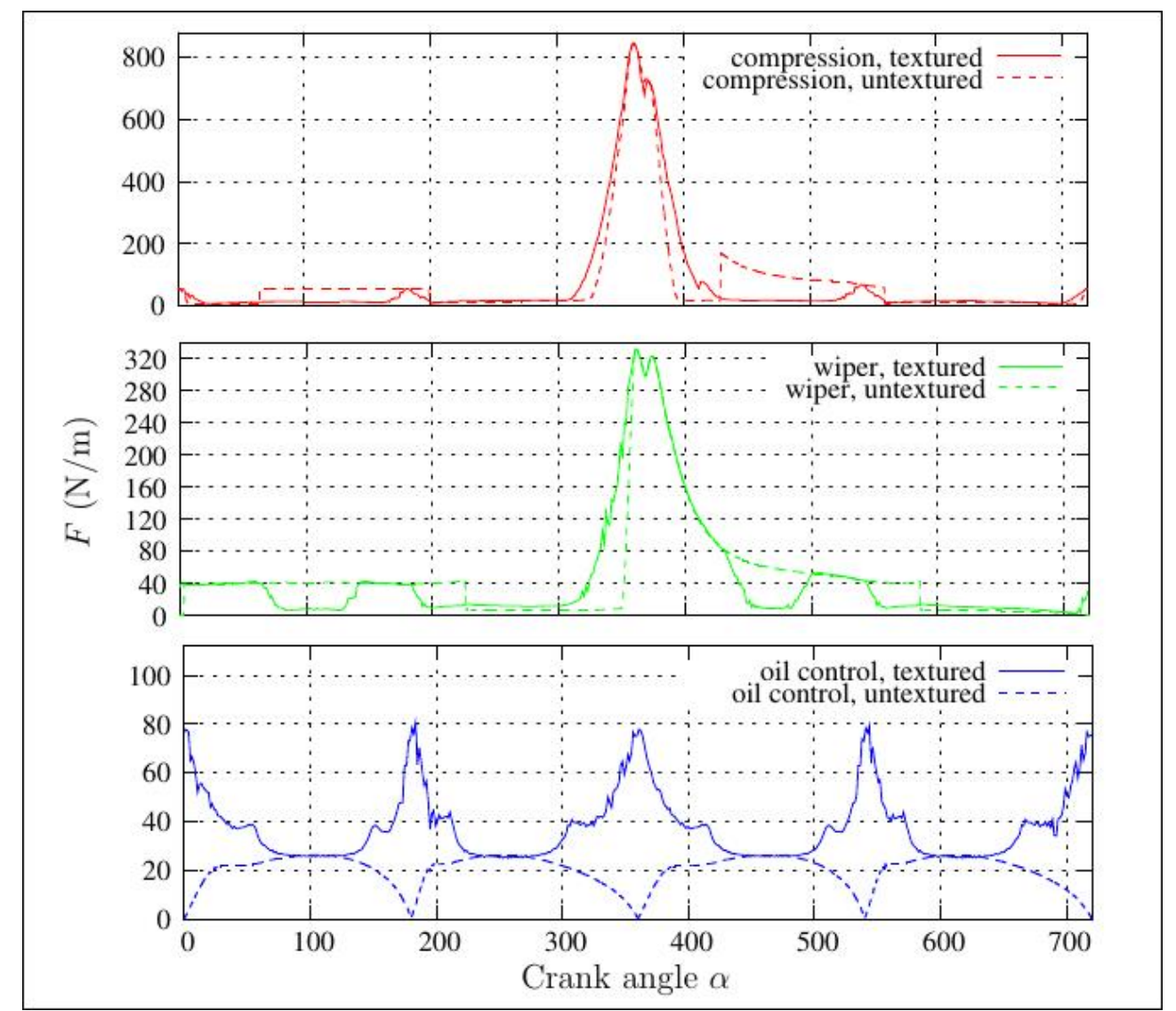

Figure 5: Total friction force in each ring.

* Technical contribution to the $2^{\text {nd }}$ International Brazilian Conference on Tribology - TriboBR 2014, November $3^{\text {rd }}$ to $5^{\text {th }}$, 2014, Foz do Iguaçu, PR, Brazil. 

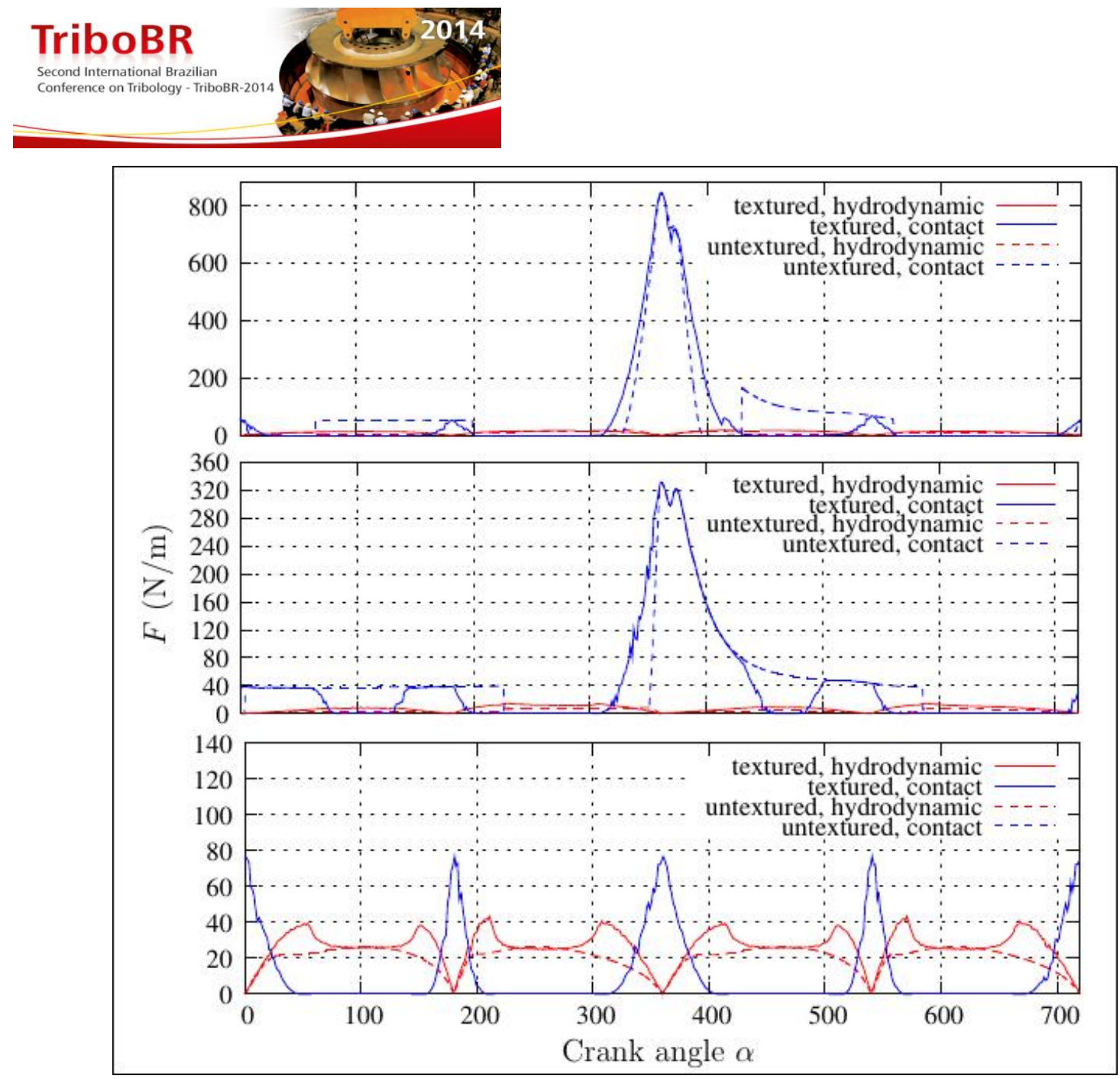

Figure 6: Friction force separated in its hydrodynamic and contact components, from top to bottom: compression, wiper and oil control ring.

\section{CONCLUSIONS}

In this article we report numerical simulations of the piston/ring liner contact for a pack of three rings: compression, wiper and oil control, along a complete cycle of a typical diesel engine running at $2000 \mathrm{rpm}$. Textures (micro dimples) inspired in those produced by Laser Surface Texturing (LST) were set all along the length of the piston stroke and their effects on clearance, friction force an power loss studied.

Simulations were possible due to an efficient and robust numerical multigrid algorithm which solves the Elrod-Adams model for lubrication with cavitation simultaneously with the ring's dynamics.

It was observed that highest friction takes place for the compression and wiper rings nearby the top dead center, in the transition from the compression to the power stroke. No improvements were seen with the textured liner in this part of the engine cycle. However, the textures had a beneficial effect at mid-stroke, where the piston endures high velocities and hydrodynamic effects are important.

These numerical experiments suggest that in order to maximize the benefits of texturing, the pocketed portion should be placed at regions with high piston velocity, leaving the regions close to the dead centers unpocketed.

\section{Acknowledgements}

The authors want to thank FAPESP (Fundação de Amparo À Pesquisa do Estado de São Paulo, Brazil, grants 2011/24147-5 and 2012/14481-8) for financial support.

* Technical contribution to the $2^{\text {nd }}$ International Brazilian Conference on Tribology - TriboBR 2014, November $3^{\text {rd }}$ to $5^{\text {th }}$, 2014, Foz do Iguaçu, PR, Brazil. 


\section{REFERENCES}

1 Holmberg K, Andersson P, Erdemir A. Global energy consumption due to friction in passenger cars. Tribology International. 2012; 47:221-234.

2 Tomanik E, Ferrarese A. Low friction ring pack for gasoline engines. In: ASME 2006 Internal Combustion Engine Division Fall Technical Conference; 2006. p. 449-455.

3 Ryk G, Etsion I. Testing piston rings with partial laser surface texturing for friction reduction. Wear. 2006; 261:792-796.

4 Dobrica M, Fillon M, Pascovici M, Cicone T. Optimizing surface texture for hydrodynamic lubricated contacs using a mass-conserving numerical approach. Proc IMechE. 2010; 224:737-750.

5 Gadeschi G, Backhaus K, Knoll G. Numerical Analysis of Laser-Textured Piston-Rings in the Hydrodynamic Lubrication Regime. Journal of Tribology. 2012 October; 134:041702-1-041702-8.

6 Checo H, Ausas R, Jai M, Cadalen JP, Choukroun F, Buscaglia G. Moving textures: Simulation of a ring sliding on a textured liner. Tribology International. 2014; 72:131142.

7 Ryk G, Kligerman Y, Etsion I. Experimental investigation of laser surface texturing for reciprocating automotive components. Tribol Trans. 2002; 45:444-449.

8 Kligerman Y, Etsion I, Shinkarenko A. Improving tribological performance of piston rings by partial surface texturing. Journal of Tribology. 2005; 127(3):632-638.

9 Tomanik E. Modelling the hydrodynamic support of cylinder bore and piston rings with laser textured surfaces. Tribology International. 2013; 59:90-96.

10 Guo Z, Yuan C, Peng Z, Yan X. Study on Influence of Cylinder Liner Surface Texture on Lubrication Performance for Cylinder Liner-Piston Ring Components. Tribology Letters. 2013; 51:9-23.

11 Bifeng Y, Li X, Fu Y, Yun W. Effect of laser textured dimples on the lubrication performance of cylinder liner in diesel engine. Lubrication Science. 2012; 24:293-312.

12 Liao K, Liu Y, Kim D, Urzua P, Tian T. Practical challenges in determining piston ring friction. Proceedings of the Institution of Mechanical Engineers, Part J: Journal of Engineering Tribology. 2012; 227 (2):112-125.

13 Elrod HG, Adams M. A computer program for cavitation. Technical report 190. 1st LEEDS LYON Symposium on Cavitation and Related Phenomena in Lubrication, IME. 1974;103:354.

14 Zhang J, Meng Y. Direct observation of cavitation phenomenon and hydrodynamic lubrication analysis of textured surfaces. Tribology Letters. 2012; 46:147-158.

15 Greenwood J, Williamson J. Contact of Nominally Flat Surfaces. Proceedings of the Royal Society of London Series A, Mathematical and Physical Sciences. 1966; 295:300-319.

16 Panayi A, Schock H. Approximation of the integral of the asperity height distribution for the Greenwood-Tripp asperity contact model. Proceedings of the Institution of Mechanical Engineers, Part J: Journal of Engineering Tribology. 2008; 222:165-169.

17 Ausas R, Jai M, Buscaglia G. A Mass-Conserving Algorithm for Dynamical Lubrication Problems With Cavitation. ASME Journal of Tribology. 2009; $131: 031702$ (7 pages). Venner C, Lubrecht A. Multilevel methods in lubrication. Elsevier; 2000.

* Technical contribution to the $2^{\text {nd }}$ International Brazilian Conference on Tribology - TriboBR 2014, November $3^{\text {rd }}$ to $5^{\text {th }}$, 2014, Foz do Iguaçu, PR, Brazil. 